\title{
Title: How are parents affected when their child has an appearance altering injury?
}

\section{Abstract}

Children are at a high risk for experiencing a burn injury. Burn injuries can result in periods of hospitalisation, painful medical procedures and permanent scarring. Although many children cope well, a burn injury can increase the likelihood of children experiencing psychosocial difficulties such as body image concerns, social anxiety and post-traumatic stress symptoms (PTSS). Parents can also be affected by their child's burn and are at risk of experiencing psychosocial difficulties such as elevated stress, anxiety, depression and PTSS, as well as martial, domestic and financial difficulties. Research indicates that parental coping predicts how well a child adjusts to their burn injury. It is vital for parents' psychological needs to be identified and for specialist psychological support to be provided to ensure that parents feel equipped to cope with supporting their child and to reduce any potential long term difficulties for parents themselves and their the family.

\section{$\underline{\text { Key words }}$}

- Burn Injury

- Scarring

- Parents

- Psychological well-being

To cite this article: Griffiths, C. (2016). How are parents affected when their child has an appearance-altering injury?. Journal of Aesthetic Nursing, 5(2), 79-81.

\section{Introduction}

What is a burn injury and how are children affected?

A burn is an injury to the skin caused by heat or due to radioactivity, radiation, electricity, contact with chemicals or friction (World Health Organisation, 2015). Children are at a high risk of suffering a burn injury. In the UK approximately 6400 children attend hospital for a burn injury each year (National Burn Care Review, 2001). For many children, the experience of a burn involves a period of time in hospital, painful medical treatment and permanent scarring (Hamaoui et al, 2006). For some children the presence of scarring can result in unwanted attention, staring, questions or negative comments from others (Blakeney et al, 1998; Lawrence et al, 2004; McGarry et al, 2014; Rimmer et al, 2007). Many children cope 
well and are unaffected by their burn injury. However the experience of a burn can increase the likelihood that children experience psychosocial difficulties after the event such as anxiety, depression, social skills difficulties and post-traumatic stress disorder (Hall et al, 2006; Horridge, et al, 2010; Meyer et al, 1995; Stoddard, et al, 1992). Experiencing a burn injury during childhood (an already challenging developmental period), can add further pressure, increasing the likelihood that important developmental processes are disturbed (Bakker et al, 2013a). Consequently, research has found that a significant number of adults burnt as children report elevated levels of anxiety and emotional disorders as adults (Bakker et al, 2013a). Therefore it is important to provide the most effective support to children who have experienced a burn injury, in order to reduce any potential challenges they may experience as children and later on as adults.

How can parents themselves be affected when supporting their child with a burn?

A vital factor which influences how a child adjusts to a burn injury is the parents' reaction to the injury, their ability to support their child in their treatment and manage other people's reactions to the injury and scarring (Hamaoui, et al, 2006; Noronha et al, 2007). Many parents cope well with supporting their child and managing their associated treatment. However, some parents can be affected by the trauma of the burn injury. Research indicates that supporting a child with a burn injury can place significant psychological demands on parents (Bakker et al, 2013a). A burn injury can be particularly demanding and can place unique stressors for parents to cope with. Firstly, burn injuries are typically the result of acute trauma, leaving parents unprepared for the psychological and practical demands of supporting a child with a burn. Additionally, a burn injury is often linked with perceived or actual parental neglect. This can increase the likelihood that parents will have to experience and manage feelings of guilt. Lastly, a burn injury can result in a child being left with permanent scarring which may trigger further feelings of guilt and parents may experience a sense of mourning over the loss of their child's appearance (Cella, et al, 1988).

Evidence suggests that parents are at risk for experiencing stress, anxiety and depression when supporting a child with an appearance altering injury such as a burn (Hamaoui, et al, 2006). Some parents can also experience symptoms of post-traumatic stress (De Young, et al, 2014). These symptoms are characterised by emotional distress and by two different states of mind: avoidance and intrusion (Horowitz, 1986). Avoidance involves the suppressing and numbing of emotions, avoidance behaviours (e.g. often situations that are associated with the burn injury) and a lack of interest in activities that were enjoyed previously. Intrusion involves the sudden experience of distressing thoughts, memories, feelings or flashbacks related to the burn injury, either the event itself or experiences related to it (e.g. travelling in the ambulance or watching medical staff administer wound treatment) (Cella, et al, 1988). Parents can struggle with both these states of mind when supporting their child with a burn, particularly if their child requires ongoing medical 
treatment or has scarring, which can be a reminder of the traumatic event (Miles, et al, 1984).

For most parents, post-traumatic stress symptoms decrease over time and they do not experience any long term negative effects of the burn injury. However a significant proportion of parents experience chronic post-traumatic stress symptoms (Bakker, et al, 2013a; De Young et al, 2014). Experiencing these symptoms over a long period of time can affect how well a parent is able to care for themselves and their child. Chronic parental PTSS has been also found to contribute to the development and maintenance of child PTSS (Bakker et al, 2013b; De Young et al, 2014). Therefore it is vital that parents' emotional needs are identified and appropriate support is provided.

As well the emotional impact, there are many practical obstacles that parents are faced with. For children with more complicated injuries which result in a prolonged hospital stay, parents are often required to take long periods off work and some may need to quit their job altogether to support their child. There are also the financial implications when parents are visiting their child in hospital, such as accommodation (if the family lives far away from the hospital) and general living and transport expenses such as food and petrol.

Even once a child is back at home, parents at risk of experiencing further stress since they are often responsible for daily wound and scar management procedures such as dressing changes, pressure garment application, creaming, massage and washing and dressing their child, at a time when children can be experiencing extreme discomfort and pain because of their burn injury (Horridge et al, 2010). Particularly in the early weeks after the injury, these experiences can be distressing and painful for some children, and for parents to witness their child in pain can further increase parents' stress (McGarry et al, 2014).

For some parents the marital relationship can also be affected by the burn. For example it can become strained if both parents are trying to manage their jobs and child caring responsibilities. Similarly the burn injury can result in the typical roles that parents have in the household changing, for example one parent may start to take responsibility for more aspects of the housework or childcare and these changing roles can sometimes increase tensions between partners (Griffiths et al, in preparation; Horridge et al, 2010). Parents may feel overwhelmed with guilt over their child's injury and this can place further pressure on the martial relationship (McGarry et al, 2014).

Equally, research also indicates that parents can report positive experiences from supporting their child with a burn, with marital relationships becoming stronger and parents feeling closer to their partner and their family because of going through the experience together. Parents have also reported a new found self-confidence for dealing with stressful situations after going through the experience (Griffiths et al, in preparation). 
It may seem intuitive that the more severe a child's burn injury, the more likely that parents will have difficulty supporting them. However this has not been found to be true, with research indicating that the severity of a child's burn injury does not predict parental distress (Phillips \& Rumsey, 2008). This suggests that all parents (irrespective of the severity of their child's burn) are at risk of experiencing psychological difficulties when supporting their child.

Clearly the impact of supporting a child with a burn injury can place significant demands on parents themselves. Although many families cope very well, it is vital that healthcare providers ensure that families have access to specialist tailored support to ensure that parents feel able to cope with supporting their child and to reduce any potential long term difficulties for parents themselves and their the family.

What support is available for parents' supporting a child with a burn?

The NHS Burn service provides specialist psychosocial support for those affected by burns and their families. Most burn services have a psychosocial specialist such as a clinical psychologist, psychotherapist or counsellor that can provide one-to-one psychological support for parents with a burn. Research has identified that parents report being very satisfied with the psychological support that they received in the NHS (Griffiths, et al, in preparation). However it can also be sometimes hard for health professionals to identify difficulties that parents are experiencing, since parents are often so focused on supporting their child that they might not wish to receive support themselves and therefore may choose not to report their concerns or accept support offered to them (Griffiths et al, in preparation). In order to ensure that parents' needs are appropriately identified, it has been recommended that routine psychological screening should be conducted for parents supporting a child with a burn (Phillips \& Rumsey, 2008).

In addition to the NHS Burn service there are also a number of UK based charities that provide support for parents supporting a child with a burn. The Katie Piper Foundation (http://katiepiperfoundation.org.uk/) provides support for those affected by burns and their families. The charity Changing Faces (https://www.changingfaces.org.uk/Home) provides support for people who have an injury or condition that affects appearance such as burn scars. Alternatively there are also a number regional burn clubs associated with the British Burns Association that offer parents an opportunity to meet other parents who are supporting a child with a burn in order to offer and receive peer support from others in a similar situation (http://www.britishburnassociation.org/burn-camps).

Overall research indicates that parental coping is a vital factor for predicting a child's adjustment to a burn injury. However parents can also be significantly affected by a burn. Routine psychological screening for parents supporting a child with a burn would ensure that all parents' needs are identified and increase the likelihood that parents receive the best possible support. 


\section{Summary sentences}

- A burn injury can increase the likelihood of children and their parents experiencing psychosocial difficulties.

- Parental coping is a predictor of child adjustment to a burn.

- $\quad$ Routine psychological screening should be conducted for parents supporting a child with a burn.

- Parents need access to specialist psychological support to reduce any potential long term difficulties for parents themselves and their family.

\section{$\underline{\text { References }}$}

Bakker, A., Maertens, K. J., Van Son, M. J., \& Van Loey, N. E. (2013a). Psychological consequences of pediatric burns from a child and family perspective: A review of the empirical literature. Clinical Psychology Review, 33 (3): 361-71.

Bakker, A., Van der Heijden, P. G., Van Son, M. J., \& Van Loey, N. E. (2013b). Course of traumatic stress reactions in couples after a burn event to their young child. Health Psychology, 32(10), 1076.

Blakeney P, Robert R, \& Meyer WJ. (1998). Psychological and social recovery of children disfigured by physical trauma: Elements of treatment supported by empirical data. International Review of Psychiatry, 10(3): 196b-201b.

British Burns Association. (2001). National burns care review Committee report: standards and strategy for burn care: a review of burn care in the British Isles.

Cella, D. F., Perry, S. W., Poag, M. E., Amand, R., \& Goodwin, C. (1988). Depression and stress responses in parents of burned children. Journal of Pediatric Psychology, 13(1), 87-99.

De Young, A. C., Hendrikz, J., Kenardy, J. A., Cobham, V. E., \& Kimble, R. M. (2014). Prospective evaluation of parent distress following pediatric burns and identification of risk factors for young child and parent posttraumatic stress disorder. Journal of Child and Adolescent Psychopharmacology, 24(1), 9-17.

El Hamaoui, Y., Yaalaoui, S., Chihabeddine, K., Boukind, E., \& Moussaoui, D. (2006). Depression in mothers of burned children. Archives of Women's Mental Health, 9(3), 117119. 
Griffiths et al (in preparation). The parental impact of supporting a child with a burn injury.

Hall E, Saxe G, Stoddard F, Kaplow J, Koenen K, Chawla N, et al. (2006). Posttraumatic stress symptoms in parents of children with acute burns. Journal of Pediatric Psychology, 31:40312.

Horridge, G., Cohen, K., \& Gaskell, S. (2010). BurnEd: Parental, psychological and social factors influencing a burn-injured child's return to education. Burns, 36 (5), 630-638.

Horowitz, M. J. (1986). Stress-response syndromes: A review of posttraumatic and adjustment disorders. Psychiatric Services, 37(3), 241-249.

Lawrence, J. W., Fauerbach, J. A., Heinberg, L., \& Doctor, M. (2004). THE 2003 CLINICAL RESEARCH AWARD: Visible vs Hidden Scars and Their Relation to Body Esteem. Journal of Burn Care \& Research, 25(1), 25-32.

McGarry, S., Elliott, C., McDonald, A., Valentine, J., Wood, F., \& Girdler, S. (2014). "This is not just a little accident": a qualitative understanding of paediatric burns from the perspective of parents. Disability \& Rehabilitation, 37(1), 41-50.

Meyer W, Blakeney P, LeDoux J, \& Herndon D (1995). Diminished adaptive behaviors among pediatric survivors of burns. Journal of Burn Care and Rehabilitation, 16, 511-8.

Miles, M. S., Carter, M. C., Spicher, C., \& Hassanein, R. (1984). Maternal and paternal stress reactions when a child is hospitalized in a pediatric intensive care unit. Issues in Comprehensive Pediatric Nursing, 7(6), 333-342.

Noronha, D. O., \& Faust, J. (2007). Identifying the variables impacting post-burn psychological adjustment: A meta-analysis. Journal of Pediatric Psychology,32(3), 380-391.

Phillips, C., \& Rumsey, N. (2008). Considerations for the provision of psychosocial services for families following paediatric burn injury-a quantitative study. Burns, 34(1), 56-62.

Rimmer, R. B., Foster, K. N., Bay, C. R., Floros, J., Rutter, C., Bosch, J., ... \& Caruso, D. M. (2007). The reported effects of bullying on burn-surviving children. Journal of burn care \& research, 28(3), 484-489.

Stoddard FJ, Stroud L, Murphy M. Depression in children after recovery from severe burns. (1992). Journal of Burn Care and Rehabilitation, 13: 340-7. 